Saudi Journal of Medicine

Abbreviated Key Title: Saudi J Med ISSN 2518-3389 (Print) |ISSN 2518-3397 (Online)

\title{
Premilinary Results of Surgical Results of Total Hip Joint Replacement at the 7A Military Hospital
}

\author{
Quang-Tri Lế ${ }^{*}$ and Thanh-Hoang Nguyen \\ Department of Orthopedic, 7A Military Hospital 466 Nguyen Trai Street, Ward 8, District 5, Ho Chi Minh City, 72706 Vietnam
}

DOI: $10.36348 /$ sjm.2020.v05i01.001 $\quad$ | Received: 28.12.2019| Accepted: 04.01.2020 | Published: 08.01.2020

*Corresponding author: Quang-Tri Le, MD, PhD

Abstract

Purpose: Initial assessment of total hip replacement surgery at 7A Military Hospital. Subjects and research methods: A cross-sectional descriptive study, conducted from 3/2014 - 4/2018 on 47 patients with a total of 52 total hip joints (THJ) were replaced at 7A Military Hospital. Result: The average time of surgery was $91.92 \pm 15,847$ minutes. The average length of treatment: $15.5 \pm 4,948$ days. Evaluation by HARRIS score: Very good + good: $96.2 \%$, Average + poor $3.8 \%$. Complications: Superficial Infections on incision $1.9 \%$, dislocated joints $1.9 \%$, loose stem $1.9 \%$, no serious complications. Conclusion: Total hip joint replacement to treat osteoarthritis, aseptic necrosis of femoral head, femoral neck fracture is an effective treatment, restoring the patients' joint movement function, and with low complication rate. Keyword: Surgery, total hip replacement, (THJ), osteoarthritis.

Copyright @ 2020: This is an open-access article distributed under the terms of the Creative Commons Attribution license which permits unrestricted
use, distribution, and reproduction in any medium for non-commercial use (NonCommercial, or CC-BY-NC) provided the original author and source
are credited.

\section{INTRODUCTION}

In orthopedic injuries, we often encounter severe anatomical lesions in the hip as the results of many diseases such as trauma (acetabulum rupture, femur neck fracture), osteoarthritis, and aseptic necrosis of femoral head. In the early stages of these diseases, it is possible to choose conservative treatments [1].

However, most patients come for examination at the later stage. Conservation treatments are no longer useful. The hip replacement surgery becomes a possible beneficial treatment for the patients. Depending on the patient's situation, the options can be partial or total hip replacement [1].

Total hip replacement is a surgery to remove all the damaged cartilage and epiphyseal bone of the acetabulum and femoral head, and then replace them with a total artificial joint including artificial acetabulum, femoral head and a stem placed into the hollow center of the femur $[1,2]$.

This technique was proposed and implemented by Charnley in 1958 and has been widely used all over the world in order to help the patient reduce pain, increase joint activity, and repair deformations [3].

Today, total hip replacement surgery is an orthopedic surgery widely applied worldwide, with
80,000 to 100,000 hip joints being replaced annually [1].

In Vietnam, total hip joint replacement surgery was first performed by Tran Ngoc Ninh in Saigon and Ngo Bao Khang in Hanoi. Since then, this technique has been increasingly developed and widely applied in the country $[4,5]$.

7A Military Hospital, hip joint replacement surgery has been implemented since 2013 and has achieved certain results. In order to make a more detailed and comprehensive assessment of the results and limitations of the technique, we researched the subject: "Evaluation of the results of total hip replacement surgery at 7A Military Hospital" aiming at initially assessing the results of total hip replacement surgery at 7A Military Hospital.

\section{SUBJECT AND RESEARCH METHOD Subjects of the research}

The research subjects are 47 patients with total hip joint replacement in 7A Military Hospital, including 20 retrospective patients, 27 prospective patients, 5/47 patients who had the hip joint replacement in both sides, making a total of 52 joints replaced.

\section{Criteria for patient selection}

- The patient had had total hip joint replacement surgery. 
- Having full medical records, taking X-ray images before and after surgery, and having a clear address.

- Patients came for follow-up as scheduled.

\section{Exclusion criteria}

- Patients who did not meet the above criteria.

\section{Equipment and artificial joints}

- Complete hip replacement surgery kits.

- Artificial implants for cement and cementless application with full-size range (from 44 to 64).

Study time: From March 2014 to April 2018

Research location: 7A Military Hospital, Ho Chi Minh City, Viet Nam.

Research Methods: Clinical description (including retrospective and prospective studies)

- Research design: cross-sectional description

- Sample selection method: Convenient sample selection.

\section{Clinical symptoms}

Table-1: Clinical symptoms $(n=47)$

\begin{tabular}{|c|c|c|c|c|}
\hline \multirow{2}{*}{ Sype } & \multicolumn{2}{|c|}{ Limit hip movement } & \multirow{2}{*}{$\begin{array}{l}\text { Loss of hip } \\
\text { movement }\end{array}$} & \multirow[t]{2}{*}{ Short limbs } \\
\hline & One side & Two sides & & \\
\hline Yes & $\begin{array}{c}7 / 47 \\
(\mathbf{1 4 . 9 \% )})\end{array}$ & $\begin{array}{c}25 / 47 \\
(\mathbf{5 3 . 2 \% )}\end{array}$ & $\begin{array}{c}14 / 47 \\
(\mathbf{2 9 . 8 \% )}\end{array}$ & $\begin{array}{c}14 / 47 \\
(\mathbf{2 9 . 8 \% )}\end{array}$ \\
\hline No & $\begin{array}{c}40 / 47 \\
(\mathbf{8 5 . 1 \% )}\end{array}$ & $\begin{array}{c}22 / 7 \\
\mathbf{( 4 6 . 8 \% )}\end{array}$ & $\begin{array}{c}33 / 47 \\
\mathbf{( 7 0 . 2 \% )}\end{array}$ & $\begin{array}{c}33 / 47 \\
\mathbf{( 7 0 . 2 \% )}\end{array}$ \\
\hline Total & $47(100 \%)$ & $47(100 \%)$ & $47(100 \%)$ & $47(100 \%)$ \\
\hline
\end{tabular}

Comment: + Limiting hip movement in one side $7 / 47$ (14.9\%)

+ Restricting hip joint movement in both sides $25 / 47$ (53.2\%)

$+14 / 47(29.8 \%)$ of hip fracture cases lost joint movement, and have clear short limb.

\section{Injury on X-ray}

Table-2: Pre-surgery X-ray results $(n=47)$

\begin{tabular}{|c|c|c|c|c|}
\hline \multirow{2}{*}{ X-ray } & Osteoarthritis & $\begin{array}{c}\text { Femoral neck } \\
\text { fracture }\end{array}$ & $\begin{array}{c}\text { Femoral head aseptic } \\
\text { necrosis }\end{array}$ & \multirow{2}{*}{ Total } \\
\cline { 2 - 5 } & Quantity $(\%)$ & Quantity $(\%)$ & Quantity (\%) & \\
\hline G3, G4 Femoral neck fracture & 0 & $14(100 \%)$ & 0 & $14(100 \%)$ \\
\hline Narrow joint space & $6(100 \%)$ & 0 & 0 & $6(100 \%)$ \\
\hline $\begin{array}{c}\text { Combination with former } \\
\text { Femoral neck fracture }\end{array}$ & 0 & 0 & $22(100 \%)$ & $22(100 \%)$ \\
\hline Total & 0 & 0 & $5(100 \%)$ & $5(100 \%)$ \\
\hline
\end{tabular}

\section{Comments}

+ 6 patients with Osteoarthritis on X-ray showed typical narrow joint space.

+ In 27 patients who had aseptic necrosis, there were five patients having previous femoral neck fractures.

+ The remaining 14 patients had X-ray images of typical G3, G4 femoral neck fractures. 


\section{Surgical results}

Early results

Table-3: Early results after joint surgery $(n=52)$

\begin{tabular}{|c|c|c|c|c|}
\hline \multicolumn{3}{|c|}{ Postoperative results } & Case \#: & Percentage \% \\
\hline \multirow{2}{*}{\multicolumn{2}{|c|}{ Complications during surgery }} & Yes & 0 & $0 \%$ \\
\hline & & No & 52 & $100 \%$ \\
\hline \multirow{4}{*}{$\begin{array}{c}\text { X-ray } \\
\text { after } \\
\text { surgery }\end{array}$} & \multirow{2}{*}{$\begin{array}{l}\text { Acetabulum in the right } \\
\text { position }\end{array}$} & Yes & 52 & $100 \%$ \\
\hline & & No & 0 & $0 \%$ \\
\hline & \multirow{2}{*}{ Correct stem, head } & Yes & 52 & $100 \%$ \\
\hline & & No & 0 & $0 \%$ \\
\hline \multirow{6}{*}{$\begin{array}{c}\text { Early } \\
\text { complicati } \\
\text { ons }\end{array}$} & \multirow{2}{*}{ Bleeding } & Yes & 0 & $0 \%$ \\
\hline & & No & 52 & $100 \%$ \\
\hline & \multirow{2}{*}{ Infection of the incision } & Yes & 1 & $1.9 \%$ \\
\hline & & No & 51 & $98.1 \%$ \\
\hline & \multirow{2}{*}{ Dislocate } & Yes & 1 & $1.9 \%$ \\
\hline & & No & 51 & $98.1 \%$ \\
\hline \multicolumn{2}{|c|}{ Average surgery time } & & \multicolumn{2}{|c|}{$\begin{array}{c}91.92 \text { minutes } \pm 15.847 \\
\text { (Minimum: 60; Maximum: } 120 \text { ) }\end{array}$} \\
\hline \multicolumn{2}{|c|}{$\begin{array}{c}\text { The total duration of treatment from } \\
\text { admission to discharge }\end{array}$} & & \multicolumn{2}{|c|}{$\begin{array}{c}15.5 \text { days } \pm 4,948 \\
\text { (Minimum: } 8 \text {; maximum: } 31 \text { ) }\end{array}$} \\
\hline
\end{tabular}

\section{Comments}

- $100 \%$ of cases do not have any complications during surgery.

- The primary intention healing of the incision accounted for $98.1 \%$. There was 1 case of superficial infection of the wound on the 3rd day after surgery $(1.9 \%)$.

- X-ray results after surgery: Correct positioning of the acetabulum was $100 \%$, and of the stem and head was $100 \%$.
- The average surgery time was 91.92 minutes; the shortest was 60 minutes; the longest was 120 minutes.

- The average duration of treatment from admission to discharge was 9.52 days; the shortest time was 8 days; the longest time was 31 days.

\section{Long term results}

Table-4: Evaluate HARRIS W.H score by artificial joint type $(n=52)$

\begin{tabular}{|c|c|c|c|c|c|}
\hline Ranking & $\begin{array}{l}\text { Very good } \\
(90-100 p)\end{array}$ & $\begin{array}{c}\text { Good } \\
(80-89 p)\end{array}$ & $\begin{array}{l}\text { Average } \\
(70-79 p)\end{array}$ & $\begin{array}{l}\text { Poor } \\
<70 p\end{array}$ & \multirow{2}{*}{ Total } \\
\hline Joint type & Quantity (\%) & Quantity (\%) & Quantity (\%) & Quantity (\%) & \\
\hline Total hip replacement without cement & $14(46.7 \%)$ & $15(50 \%)$ & $0(0 \%)$ & $1(3.3 \%)$ & $30(100 \%)$ \\
\hline Total hip replacement with cement & $4(18.2 \%)$ & $17(77.3 \%)$ & $1(4.5 \%)$ & $0(0 \%)$ & $22(100 \%)$ \\
\hline Total & $18(34.6 \%)$ & $32(61.5 \%)$ & $1(1.9 \%)$ & $1(1.9 \%)$ & $52(100 \%)$ \\
\hline
\end{tabular}

\section{Comment}

- In total, 52 hip joints replaced, there were 30 cases without cement, accounted for $57.7 \%$, and 22 cases with cement, accounted for $42.3 \%$.

- HARRIS W.H scored very well in both types of hip joint replacement was $34.6 \%$ and good $61.5 \%$

- There was 1 in 30 cases of cementless replacement got a poor score, which accounted for $3.3 \%$.
- $\quad 1 / 22$ cases of hip joint replacement with cement classified as medium, accounting for $4.5 \%$

- There was no difference between 2 types of joint replacement, cementless, and cement in postoperative results evaluation according to HARRIS WH (p>0.05).

Re-examination $X$-ray results: There was1 case in which the patient fell and broke the bones and stem, accounted for $1.9 \%$.

\section{Evaluate the overall results}

Table-5: Evaluation of overall results $(n=52)$

\begin{tabular}{|c|c|c|}
\hline Results & Very good + good & Medium + poor \\
\hline Quantity & 50 & 2 \\
\hline Ratio & $96.2 \%$ & $3.8 \%$ \\
\hline Total & \multicolumn{2}{|c|}{$\mathbf{5 2 ( 1 0 0 \% )}$} \\
\hline
\end{tabular}




\section{Comments}

- Based on the HARRIS WH score and x-ray results, we evaluated the overall results as follows:

+ Very good and good were 50/52 cases, accounting for $96.2 \%$.

+ Average and poor were $2 / 52$ cases, accounting for $3.8 \%$.

\section{DISCUSSION}

\section{General characteristics of the patients}

The ages of the patients were from 19 to 69 years; the average age was 55.72 $\pm 12,311$. Mostly men $34 / 47$ accounted for $72.3 \%$. This group is the main labor in the family, leading to their family economy being seriously affected.

In our study, three common conditions cause joint replacement: Osteoarthritis, femoral neck fracture, and femoral head aseptic necrosis.

Table-6: Compared to studies of other authors

\begin{tabular}{|l|c|c|c|}
\hline Author & Causes & $\begin{array}{c}\text { Osteoarthritis } \\
\text { fracture }\end{array}$ & $\begin{array}{c}\text { Femoral head } \\
\text { aseptic necrosis }\end{array}$ \\
\hline Luu H.T (2012) [4] & $63.48 \%$ & $6.95 \%$ & $29.57 \%$ \\
\hline Tran D.C (2012) [5] & $5.1 \%$ & $82.1 \%$ & 12.8 \\
\hline Our research & $12.8 \%$ & $29.8 \%$ & $54.7 \%$ \\
\hline
\end{tabular}

Regarding the causes of joint replacement in our study and some other authors were different. In our opinion, the differences in results are due to the long and short study time, the different sample sizes, and the different epidemiological characteristics. Therefore, this comparison is only an estimate and a reference.

\section{Symptoms upon admission}

Clinical manifestations: Most patients who had been diagnosed with osteoarthritis and femoral head aseptic necrosis shown typical symptoms of the acquired disease because they all came to the hospital at the later stage of the disease $(1-5$ years $)$ and had undergone medical treatment or taken traditional medicine, but the symptoms did not reduce. $100 \%$ of patients had pain, limiting movement on one or both hips.

Fourteen patients femoral head fractures mainly due to traffic accidents or domestic accidents with symptoms such as loss of mobility in the injured hip and apparent short limb.

In the study of the other Vietnamese authors $[4,5]$ or international authors [6-9] on clinical symptoms also showed similar results. The reason for the similarity is that except for patients with acute trauma (hip fracture) who would come to the hospital immediately after the accident, patients with osteoarthritis and necrosis came to the hospital at a later stage.

X-ray: In our study, there were six patients with osteoarthritis who had X-ray results of typical narrow joint spaces $(12.8 \%)$. Fourteen patients with new femoral neck fracture $(29.8 \%)$, and 27 patients with necrosis (57.4\%). In the study of Luu, 2012 [4], $41 / 67$ cases of osteoarthritis and necrosis had images of narrowing of joints on X-ray (61.2\%). 27/27 patients with necrosis showed necrotically and collapsed head. This result showed the fact that most patients with the chronic hip disease (osteoarthritis and necrosis) came to the hospital at a later stage with symptoms of severe pain and limited movement. At this stage, the medical treatment and conservation method bring minimal results; the hip replacement solution is the best treatment method.

\section{Surgical results}

In our study, the average hospitalization time was $15.5 \pm 4,948$ days, which was relatively long compared to other groups of patients. The reason was that many patients had chronic diseases such as hypertension $(23.1 \%)$ or bacterial foci on the body. Therefore, we had to treat those conditions until stable before surgery, leading to extended treatment time. Besides, hip joint replacement is major surgery, so patients needed time to practice, rehabilitate, and being monitor before releasing from the hospital. Through this study, we found that the patients needed to be treated, combining with early rehabilitation after surgery in order to make the hospitalization time shorter.

\section{Evaluate the early results}

There was one patient (1.9\%) had a superficial infection on the incision the 3rd day after surgery. The patient was treated; daily bandages changed, given combination antiseptic, and got the incision back to normal on day eighth. The case also raised concerns in terms of before and after surgery sterilization. According to Jonsson et al. 2014 [10], the deep infection rate after the hip replacement was $1 \%$, the superficial infection was more common with $3 \%$.

There was 1 case of dislocated hip groin 16 days after discharge, due to falling (1.9\%). The patient was then back to the hospital for testing and had hip replacement surgery again after six days. The postoperative was stable. The rate of dislocated joints after the hip replacement was $2 \%[11,12]$. 
Long term results upon follow-up visits

Based on HARRIS W.H score and the results of $\mathrm{X}$-ray examination, we got the following assessment results:
+ Very good and good were 50/52 cases accounting for $96.2 \%$

+ Average and poor were $2 / 52$ cases, accounting for $3.8 \%$.

Table-7: Compare with other authors

\begin{tabular}{|l|c|c|c|}
\hline \multicolumn{1}{|c|}{ Results } & Very good + good & Average & Poor \\
\hline Domestic [4,5] & $95.5 \%$ & $2.7 \%$ & $1.8 \%$ \\
\hline International $[6,7,8,9]$ & $96.15 \%$ & $3.85 \%$ & $0 \%$ \\
\hline Our research & $96.2 \%$ & $1.9 \%$ & $1.9 \%$ \\
\hline
\end{tabular}

We found that the results of our study and some other authors were similar [4-9]. Although in our study the study period was not long, the number of patients was not large, and there were still some cases with a medium and poor score, results still showed that total hip joint replacement is a promising method to treat hip disease (osteoarthritis, aseptic necrosis, and femoral neck fracture).

\section{CONCLUSIONS}

Total hip joint replacement is effective in treating osteoarthritis, femoral head aseptic necrosis, and femoral neck fracture; help restore the ability of hip movements to patients. Good and very good results reached $96.2 \%$.

\section{DECLARATION}

Scientific Responsibility Statement: The authors declare that they are responsible for the article's scientific content including study design, data collection, analysis and interpretation, writing, some of the main line, or all of the preparation and scientific review of the contents and approval of the final version of the article.

Animal and human rights statement: All procedures performed in this study were in accordance with the ethical standards of the institutional and/or national research committee and with the 1964 Helsinki declaration and its later amendments or comparable ethical standards. No animal or human studies were carried out by the authors for this article.

\section{CONFLICT OF INTEREST}

None of the authors received any type of financial support that could be considered potential conflict of interest regarding the manuscript or its submission.

\section{REFERENCES}

1. Ly, T. V., \& Swiontkowski, M. F. (2008). Management of femoral neck fractures in young adults. Indian journal of orthopaedics, 42(1), 3 .

2. Gandhi, R., Perruccio, A. V., \& Mahomed, N. N. (2014). Surgical management of hip osteoarthritis. CMAJ, 186(5), 347-355.
3. Toledo-Pereyra, L. H. (2004). John CharnleyFather of Modern Total Hip Replacement. Journal of Investigative Surgery, 17(6), 299-301.

4. Anderson, J., Neary, F., \& Pickstone, J. V. (2007). Hips, Health Services and Quality. In Surgeons, Manufacturers and Patients (pp. 106-129). Palgrave Macmillan, London.

5. Tran D. C., \& Le N.H.(2012). Total hip replacement results using the posterior approach minimally invasive technique, Vietnam J. Orthop. Trauma,12-17 (in Vietnamese).

6. El Banna, E. G. M. (2016). Conversion arthroplasty after failed dynamic hip screw fixation of intertrochanteric fractures. The Egyptian Orthopaedic Journal, 51(3), 243.

7. Siverling, S., Felix, I., Chow, S. B., Niedbala, E., \& Su, E. P. (2012). Hip resurfacing: not your average hip replacement. Current reviews in musculoskeletal medicine, 5(1), 32-38.

8. Sanders, T. L., Kremers, H. M., Schleck, C. D., Larson, D. R., \& Berry, D. J. (2017). Subsequent total joint arthroplasty after primary total knee or hip arthroplasty: a 40-year population-based study. The Journal of bone and joint surgery. American volume, 99(5), 396.

9. Karachalios, T., Komnos, G., \& Koutalos, A. (2018). Total hip arthroplasty: Survival and modes of failure. EFORT open reviews, 3(5), 232-239.

10. Jonsson, E. Ö., Johannesdottir, H., Robertsson, O., \& Mogensen, B. (2014). Bacterial contamination of the wound during primary total hip and knee replacement: median 13 years of follow-up of 90 replacements. Acta orthopaedica, 85(2), 159-164.

11. Zhu, F., Liu, G., Shao, H. G., Wang, Y. J., Li, R. Q., Yang, H. L., \& Xu, Y. Z. (2015). Treatment of femoral neck fracture with percutaneous compression plate: preliminary results in 74 patients. Orthopaedic surgery, 7(2), 132-137.

12. Little, J. P., Taddei, F., Viceconti, M., Murray, D. W., \& Gill, H. S. (2007). Changes in femur stress after hip resurfacing arthroplasty: response to physiological loads. Clinical Biomechanics, 22(4), 440-448. 